\title{
The Patient as a Partner in Prescribing: Direct-to-Consumer Advertising
}

\author{
Changes in pharmaceutical marketing methods have \\ transformed traditional practices in both medicine and \\ pharmacy over the last three decades, by introducing \\ the consumer as an active player in prescribing decisions.
}

\section{Robert P. Craig}

\section{Author}

ROBERT P. CRAIG, PHARM.D., is Assistant Vice President of Clinical Product Development, PCS Healih Systems, Inc., Scottsdale, AZ.

Copyright (C) 1998, Academy of Managed Care Pharmacy, Inc. All rights reserved.
$\mathrm{T}$ raditionally, the audience for pharmaceutical marketing was seen as limited to the health care professional responsible for selecting drug products: the physician and, to a limited extent, other health care professionals. Patients were not considered part of the medication selection process or a target audience for advertising. Since the early 1980s, several changes in health care delivery have contributed to adjustments in this narrow marketing strategy, including:

$\Delta$ rapid growth in the number of nonphysician prescribers which created a new target audience of health care professionals such as physicians' assistants and nurse practitioners;

$\Delta$ increased use of generic drugs, a proliferation of me-too drugs, and a decline in break-through developments that could sell themselves based on unique indication or clinical advantage;

A competitive pressure to shorten hospital stays which created a need to educate patients about new expectations to ensure successful home treatment; and

$\Delta$ intense competition in the health care market to maintain existing hospital beds which created new demands for cost containment that led to the concept of formulary management.

Marketing strategies can be successful only if they reach audiences who have influence. Recognizing that individual practitioners weren't alone in the decision-making process, manufacturers were forced to develop new strategies to reach the new decision makers-hospitals, nonphysician prescribers, and thirdparty payors. It was only a matter of time before manufacturers identified the ultimate consumer as an important participant, and direct-to-consumer (DTC) pharmaceutical advertising was born.

\section{REGULATING PHARMACEUTICAL ADVERTISING}

Until 1962, the Federal Trade Commission (FTC) had jurisdiction over most advertising, including advertising for all drugs. In 1962, Congress transferred responsibility for oversight of prescription drug advertising to the Food and Drug Administration (FDA), leaving jurisdiction over nonprescription, over-the-counter (OTC) drugs with the FTC. In the 1988 Federal Food, Drug, and Cosmetic Act, Congress moved jurisdiction for OTC advertising to the FDA as well. The Act gives the FDA broad authority to regulate labeling which is defined as any written, printed, or graphic matter upon or accompanying a drug that is supported by the drug's manufacturer, packager, or distributor, and advertising, which is not specifically defined in the Act but is considered to be anything other than labeling that promotes a drug product and is sponsored by the manufacturer.

Labeling and advertising must meet certain clearly established criteria before receiving FDA approval. Manufacturers must provide adequate directions for use and information that is not false or 
Table 1. Terms Describing Regulation Requirements for Direct-to-Consumer Advertising

\begin{tabular}{l|l}
\hline Major statement & $\begin{array}{l}\text { A statement that conveys all of the product's most important risk. } \\
\text { Advertisers must disclose the product's major risk in either the audio } \\
\text { or audio-and-visual parts of a broadcast presentation. }\end{array}$ \\
\hline Brief summary & $\begin{array}{l}\text { A required portion of advertisements that provides information } \\
\text { related to side effects, contraindications, and effectiveness. }\end{array}$ \\
\hline Adequate provision & $\begin{array}{l}\text { Refers to the requirements that advertisers using broadcast media } \\
\text { establish mechanisms to disseminate the product's approved or } \\
\text { permitted package labeling (drug insert) via toll-free phone } \\
\text { number, distribution to accessible sites in the community, referral } \\
\text { to health care professionals, or Internet access to information. }\end{array}$ \\
\hline Fair balance & $\begin{array}{l}\text { The requirement to present a balanced view of all clinically relevant } \\
\text { information, including risks and benefits. }\end{array}$ \\
\hline
\end{tabular}

misleading in either labeling or advertising. However, labeling requirements are more extensive and more explicit than those for advertising. For example, labeling must consist of a full package insert, while advertising must include a brief summary describing the drug's ad-verse experience profile, contraindications, warnings, precautions, and indications for use. Table 1 defines terms that are used in pharmaceutical advertising.

While labeling requires advance FDA approval, advertising does not. The FDA suggests voluntary submission of advertising; retraction and corrective action can be expensive, and any steps that will avoid regulatory censure are in the best interest of the manufacturer. In severe cases a drug is subject to seizure, and legal action can be taken against the manufacturer and its employees.

\section{DTC ADVERTISING}

When direct-to-consumer advertising of prescription drugs first appeared in the early 1980s (see Table 2), it spurred considerable debate in the medical and lay communities about its suitability and appropriateness. Between September 1983 and September 1985, the FDA requested a voluntary moratorium on DTC advertising, in order to allow the agency to explore this new form of advertising and to investigate risks and benefits. The moratorium was lifted after, the FDA determined that sufficient safeguards were in place to ensure public safety. The FDA has focused on two issues related to DTC advertising: 1) ensuring that adequate information is presented in a manner that is comprehensible to the average consumer and 2) complying with the fair-balance presentation of risks and benefits, as discussed in Table 1 . The agency's overall goal is to ensure that consumers can interpret the information provided and accurately assess promotional claims and presentations. Pros and cons as presented by advocates and opponents are described in Table 3. Ideally, pharmaceutical advertising can teach consumers principle, which calls for a balanced

Table 2. Types of Direct-to-Consumer Advertising

\begin{tabular}{l|l}
\hline Reminder & $\begin{array}{l}\text { Contains the name of the drug and very limited information; excludes all } \\
\text { other claims about the product. Reinforces name and brand loyalty. }\end{array}$ \\
\hline Help-seeking & $\begin{array}{l}\text { Encourages consumers with a particular set of symptoms to seek consul- } \\
\text { tation with their physician and discuss treatment options. Does not men- } \\
\text { tion a particular product. Forbidden if a product is the only available treat- } \\
\text { ment for a specific condition, symptom, or disease. }\end{array}$ \\
\hline Product claim & $\begin{array}{l}\text { Targets a specific prescription drug and must contain safety and efficacy } \\
\text { information. Regulations require that these advertisements comply with } \\
\text { adequate provision and fair-balance principles. }\end{array}$
\end{tabular}

about the signs, symptoms, and treatments for conditions and spur them to seek treatment.

However, consumers may misunderstand or be unable to interpret technical information. Advertising can raise false hopes or unreasonable expectations about a product and also can cause consumers to place too much emphasis on warnings about adverse experiences or contraindications. In broadcast media, advertisements are frequently of short duration, which limits the amount of information that can reasonably be transmitted. The FDA published Draft Guidance on ConsumerDirected Broadcast Advertisements in July 1997 to address some of these concerns. In particular, the Draft Guidance addresses possible mechanisms for distributing a product's brief summary and describes the FDA's expectation that adequate provision will be made for dissemination of information in connection with a specific broadcast advertisement. Figure 1 describes some mechanisms suggested in the draft. This proposal would not eliminate the need for manufacturers to comply with the "major statement" requirement, which mandates that advertisements must include a statement of any major risks associated with the product. It is also important to note that this is a draft document, not proposed or actual regulation.

Most practicing pharmacists have seen the evidence of the rapid growth and impact of DTC advertising. While resistance from health care professionals was initially high, it has diminished over the years. The following facts, cited in Competitive Media Reporting, 1996, clearly demonstrate the growth of this marketing strategy:

A Manufacturers spent $\$ 595$ million on DTC advertising in 1996;

- There has been a six-fold increase in DTC spending since 1993;

A New categories of drugs are being targeted, such as cholesterol-lowering agents and cancer therapies (Figure 2 lists categories of drugs that are frequently marketed using DTC advertising); and 
Table 3. Pros and Cons of DTC Advertising

\begin{tabular}{ll}
\hline Pros & Cons \\
\hline $\begin{array}{l}\text { Meets increasing consumer demand for } \\
\text { medical information }\end{array}$ & $\begin{array}{l}\text { Interferes with physician-patient relation- } \\
\text { ship and pressures physicians to } \\
\text { prescribe }\end{array}$ \\
\hline
\end{tabular}

Informs consumers about new treatments

Confuses the patient

Encourages people to seek medical attention for conditions or symptoms that might otherwise go untreated

Decreases the cost of health care

Promotes patient compliance

Results in unnecessary drug use
A Surveys conducted in 1989, 1992 , and 1995 indicate that about half of physicians oppose DTC advertisements, although there is some evidence that physician resistance is declining.

In addition, pharmacists report anecdotal evidence of the growing impact of DTC advertising in terms of increased numbers of consumers redeeming coupons for specific products and asking
Increases the cost of drugs

Puts emphasis on pharmaceutical treatments when other treatment options may be preferred
Figure 1. Proposed Mechanisms to Meet "Adequate Provision" Requirements for DTC Broadcast Advertising

From the FDA Draft Guidance for Industry

On Consumer-Directed Broadcast Advertisements July 1997

The draft would mandate that all information relevant to a product's indication must be communicated in user-friendly language and cannot be false or misleading in any respect.

Possible mechanisms include the following:

A A toll-free number for consumers to call for approved package labeling, with a variety of options (mail, FAX, or prerecorded message) to convey the information within a reasonable amount of time.

A A mechanism to provide technology-deprived consumers with information such as dissemination of brochures containing labeling at publicly accessible sites.

A A statement in the broadcast advertisement indicating that pharmacists, physicians, or veterinarians can provide additional information.

A An Internet address announced in the advertisement or via a toll-free number.

Copies of this draft guidance and those sections of the Code of Federal Regulations that apply to DIC advertising are available on the Internet at www.fda.gov/cder. Select "regulatory guidance" once you are on the home page, then "guidance document," then "advertising."
$80 \%$ indicated they would consider prescribing a medication if requested. Only $1 \%$ would remain with their original treatment plan.

In addition, studies have shown that once a prescriber writes a specific prescription for specific medication at a patient's request, he or she is more likely to prescribe that same drug to a patient who has not requested the drug. The impact of this advertising strategy can be both significant and sustained.

DTC spending has not been at the expense of other traditional marketing practices. It has been expanded in addition to practices like sampling, sponsorship, promotional literature, professional journals, telemarketing, and convention participation. However, funds expended on DTC marketing now exceed those spent for marketing directed at professionals. With increasing frequency, drugs (both prescription and OTC) are being advertised in newspapers, magazines, and Sunday supplements and on network television. Finally, "infomercials" (programlength commercial advertisements addressing a specific product or condition and sponsored by a drug manufacturer) also are becoming more common. Sponsorship by the manufacturer is not always completely clear to the viewer.

\section{IMPLICATIONS OF DTC ADVERTISING}

As with any other type of advertising, manufacturers wouldn't use DTC ads if they didn't work. Their impact on the practice of medicine and pharmacy has been steady and measurable.

The tone of the typical physicianpatient relationship is changing. Three decades ago, the traditional physician's role was usually that of leader and sole treatment selector. In today's environment, the emerging picture is that of a team approach, with the patient playing an essential role. Increasing consumer awareness of symptoms of disease, and particularly of methods of prevention, 
is deemed essential to both the improved health of the nation and cost containment. We've learned that health isn't much different from other economic activities: appropriate demand is ensured only when the ultimate consumer has ownership of the result. Greater involvement of patients and families has contributed to changes in length of stay in acute-care beds, nursing home placement, and general quality of life.

DTC advertising recognizes this new patient role but also plays upon weak links in the health care system. The manufacturer's interest is in increasing sales of its product. Increased demand can be appropriate but may also be inappropriate or unnecessary.

Consumers may not always be in the best position to evaluate medical information, especially if they suffer from a complex, debilitating, or fatal illness. DTC may create false hope or unrealistic expectations for those grasping for relief.

People give a particularly high level of credibility to celebrities, and advertising practices that employ celebrity testimony capitalize on this tendency. The dangers of this phenomenon can be seen in two cases in which the FDA has found use of celebrity sponsors misleading. In one ad for a nonsteroidal antiinflammatory agent, baseball legend Mickey Mantle made claims of product superiority with no expert background and the ad was taken out of circulation. More recently, the FDA forced a manufacturer to add a disclaimer to an advertisement for an antihypertensive agent promoted by Cal Ripken, Jr., the Baltimore Orioles' third baseman. The disclaimer indicates that $\mathrm{Mr}$. Ripken neither has hypertension nor uses the medication advertised.

Poor judgment or frustration may lead some consumers to place undue emphasis on certain of their symptoms upon exposure to advertising. For example, a patient may interpret a simple case of heartburn or indigestion as an ulcer and visit a physician with a preconceived notion of not only diagnosis but treatment.

Advertising also places emphasis on

Figure 2. DTC Activity by Therapeutic Class

\begin{tabular}{lc}
\hline Class & Manufacturer Expenditures \\
\hline Allergy & $\$ 161 \mathrm{M}$ \\
Cholesterol reduction & $\$ 69 \mathrm{M}$ \\
Fosamax & $\$ 28 \mathrm{M}$ \\
Contraceptives & $\$ 24 \mathrm{M}$ \\
Estrogen replacement & $\$ 22 \mathrm{M}$ \\
\hline
\end{tabular}

Source: Competitive Media Report 1996

prescription drugs, when other treatments may be less expensive, less intrusive, and more appropriate. For example, heartburn and indigestion often can be controlled by changes in lifestyle or low-cost interventions such as OTC drugs for symptomatic relief. Many other conditions can be improved or corrected similarly.

Conflict may arise when the drug requested by the patient is not on an organization's formulary. Induced demand places the prescriber in a defensive position when faced with a patient who already has determined, correctly or incorrectly, the cause of an illness and the drug of choice for its treatment. Unless health care professionals have a good understanding of an organization's formulary process and can effectively communicate with patients, dissatisfaction may arise.

The increased influence of DTC advertising demands awareness and education of all prescribers and pharmacists, anticipation of its effect on demand, and open, honest communication

\section{CONCLUSION}

Health care professionals may be uncomfortable with DTC advertising due to their belief that medications are not commodities like pencils or automobiles, but complex curative agents with the potential to do great harm as well as good.

Many older pharmacists remember receiving prescriptions marked "Do not label," a practice that was not only common but unquestioned. Medications were dispensed with directions but no drug name, the assumption being that the patient had no need to know. In the 1960 s and 1970s, labeling practices were changed due to recognition that labeling prescription medications afforded an element of safety-not only would patients know their medications, but the information could be shared with other prescribers or used if an overdose occurred.

In this and other ways, the medical profession began including the patient as a partner in successful treatment. Direct-to-consumer advertising is the next step in the process of involving the patient. With or without support from the medical community, DTC will continue to exert pressure on our systems. We must prepare, respond, and educate.

Successful DTC advertising should increase sales for drug manufacturers. If the task is approached intelligently, managed health care can emphasize the positive aspects of this advertising. Differential diagnosis may occur earlier, helping to decrease morbidity and prevent long-term complications. This is an opportunity to educate patients and help them understand some of the processes we use to improve health while controlling cost. This is also an opportunity for prescribers to involve patients more and to increase their satisfaction with health care. This includes early diagnosis and treatment of commonly underdiagnosed diseases, such as depression and adult-onset diabetes, as well as promotion of healthy behaviors and compliance with effective and appropriate drug therapy. 